\title{
TEXTO E AUTORIA EM GESTOS DE LEITURA E ESCRITA NO ENEM
}

\author{
MAGNA LEITE CARVALHO LIMA ${ }^{1}$ \\ Faculdade de Filosofia, Ciências e Letras Eugênio Pacelli \\ Universidade do Vale do Sapucaí \\ Av. Pref. Tuany Toledo, 470. 37550-000. Pouso Alegre, MG, Brasil
}

magnaleite30@gmail.com

\begin{abstract}
Resumo. O objetivo deste artigo é identificar como um candidato se constitui autor em sua produção de texto e atribui significação à Proposta de Redação do Exame Nacional do Ensino Médio (ENEM), aplicado no ano de 2014. Para isso, discorremos sobre algumas noções como leitura, escrita, alfabetização e letramento, que ancoram nossas discussões e análises. Em função do objeto de estudo aqui privilegiado, tecemos algumas considerações sobre texto e autoria, bem como sobre o discurso legitimado de povo colonizado na história brasileira, desde a colonização. Algumas considerações sobre o ENEM e suas reformulações ao longo dos anos também foram apresentadas. Nossas considerações teórico-analíticas se fundamentam na perspectiva da Análise de Discurso francesa (AD). A análise desenvolvida tomou como corpus discursivo a Proposta de Redação do ENEM de 2014, bem como a produção textual de um candidato que prestou o Exame e obteve uma nota acima da média.
\end{abstract}

Palavras-chave: leitura; escrita; autoria; redação; ENEM.

\begin{abstract}
The purpose of this article is to identify as how a candidate constitutes an author in your own text production or assigns meaning to the Proposal of the National High School Exam Writing, applied in the year 2014. Then, we carry on about some notions such as reading, writing, literacy that anchor our discussion and analyses. Due to the privileged object of study here, we weave some considerations about text and authorship, as well as the legitimate discourse in Brazilian history since colonization. Some considerations on the National High School Exam Writing and your revisions over the years were also presented. Our theoretical and analytical considerations are based on the perspective of French Discourse Analysis. The analysis developed took as corpus discursive of the National High School Exam Writing the Proposal of 2014 as the textual production of a candidate who took the exam, getting a score above average.
\end{abstract}

Keywords: reading; writing; authorship; National High School Writing Exam.

\footnotetext{
${ }^{1}$ Doutoranda em Ciências da Linguagem no Programa de Pós-Graduação em Ciências da Linguagem da Univás.
} 


\section{Introdução}

O objetivo desta pesquisa foi identificar como um candidato ${ }^{2}$ se constitui autor em sua produção de texto e atribui significação à Proposta de Redação do Exame Nacional do Ensino Médio (ENEM), aplicado no ano de 2014. Pretendemos analisar, a partir da produção textual deste candidato, sua posição sujeito no discurso e como ele se coloca na função autor. Acreditamos que a autoria se dá quando o sujeito se insere na formação discursiva que determina o que pode e deve ser dito pelo candidato, a partir de discursos já legitimados sócio-historicamente e disseminados pela instituição escolar. Dessa forma, buscamos identificar, a partir de um percurso analítico, pistas que o texto produzido pelo candidato oferece, bem como as condições em que o texto foi produzido, pois partimos da hipótese de que tais condições nos levam a perceber posições-sujeito frente às políticas de língua que se deixam entrever na proposta de redação, em particular, e em todo o exame, de modo geral. Em outras palavras, as políticas linguísticas se ritualizam em torno de modelos de provas postos por processos seletivos como o ENEM e que administram como os sentidos devem ser lidos e reproduzidos nas provas de Redação.

Entendemos que ser constituído pela língua é condição para a efetivação dos processos de leitura e de escrita, que se inserem em determinadas condições sócio históricas e que mobilizam interpretações. A inscrição do dizer do candidato no repetível, na memória do dizer, traz à tona a questão da interpretação e da autoria que constituem o processo de leitura e de escrita, permitindo ao sujeito escolarizado se reconhecer e se legitimar como um ser do conhecimento, inclusive da língua oralizada. Logo, a memória proposta aqui não é a que remete às lembranças individuais. Estamos falando da memória discursiva, concebida numa esfera coletiva e social, responsável por produzir as condições necessárias de um funcionamento discursivo e, consequentemente, para a interpretação de textos.

Na sequência, discorremos sobre algumas noções que ancoram nossas discussões e análises, tais como as noções de leitura, escrita, alfabetização e letramento. Consideramos, com base na perspectiva da Análise de Discurso francesa (AD), que o sujeito não é origem do(s) sentido(s). Acreditamos, porém, que é a língua que permite ao sujeito - que surge como efeito do assujeitamento à linguagem - a efetivação da autoria, a partir dos gestos de leitura e de escrita. Assim, o tipo de relação que se estabelece entre língua, ensino e sujeito pode variar infinitamente, por isso mostrou-se relevante, dado o objeto de análise aqui abordado, tecermos algumas considerações sobre texto e autoria, bem como sobre o discurso legitimado de povo colonizado na história brasileira, desde a colonização, uma vez que, ao ser origem do dizer e produzir um texto que tenha efeito coerente, progressão e fim, o sujeito faz-se autor, mesmo inserido em uma dada conjuntura ideológica. Ainda, antes das análises, fizemos algumas considerações sobre o ENEM e suas principais reformulações.

\footnotetext{
${ }^{2} \mathrm{O}$ candidato é um egresso de uma instituição particular de ensino da cidade de Varginha - MG, na qual trabalho há 5 anos. A produção de texto é parte de uma coleta de dados, fruto de pesquisas anteriores. Essa produção foi selecionada para este estudo por ser considerada pela banca corretora do ENEM um texto acima da média, cuja nota final foi 960 pontos de um total de 1000 pontos. [cf.] LIMA, Magna Leite Carvalho. Indícios de autoria nas produções de texto de candidatos do ENEM 2012. Três Corações, 2014. Dissertação de Mestrado. Universidade do Vale do Rio Verde - UNINCOR. Três Corações, 2014.
} 


\section{Leitura e escrita, alfabetização e letramento}

Auroux (2009) assevera que gramatização é o processo que conduz a descrever e instrumentar uma língua com base em alguns pilares, entendidos como um instrumento linguístico de tecnologias de linguagem. O conceito de gramatização proposto por Auroux $(2009$, p. 65), leva em consideração que este é um processo que "conduz a descrever e instrumentalizar uma língua na base de duas tecnologias, que são ainda hoje os pilares de nosso saber metalinguístico: a gramática e o dicionário". Como um espaço linguístico está sujeito a inúmeras variações, partimos do pressuposto de que ler e escrever exigem desse sujeito que ele conheça não só as bases de uma língua, mas que seja capaz de apropriar-se dessas práticas. Além disso, entendemos que a gramatização é uma forma de legitimar um território e delimitar o espaço de uma nação, uma vez que é um processo que corresponde a uma transferência de tecnologias de uma língua para outras línguas, o que não deixa de ser uma forma de marcar território. Salientamos que o conhecimento de uma língua nacional, baseada na presença de tais instrumentos institucionalizados - como a gramática e o dicionário, por exemplo - nos traz, comumente, à memória a questão do ensino. Orlandi (2001), substancia tal afirmação quando aponta que

A nossa sociedade, do ponto de vista da linguagem, funciona com o saber e com a escrita enquanto materialidade que constitui a própria forma das instituições. A escrita é uma forma de relação social, historicamente determinada. A gramática, o dicionário são objetos de conhecimento determinados sócio-historicamente. $O$ ensino não prescinde desses objetos e dessas relações. (ORLANDI, 2008, p. 08)

Logo, não há problema em ver os instrumentos de uma maneira institucionalizada, mas é preciso ir além da observação da gramática e do dicionário na escola, para observar, conforme assevera Orlandi (2001, p. 08), seu funcionamento na relação do sujeito com a sociedade na história. Ver tais instrumentos dessa maneira os transforma em objetos vivos, "partes de um processo em que os sujeitos se constituem em suas relações e tomam parte na construção histórica das formações sociais com suas instituições, e sua ordem cotidiana" (ORLANDI, 2001, p. 08).

Partindo do pressuposto de que ler e escrever exigem do sujeito um conhecimento de como uma língua se estrutura, ao sujeito inserido em uma sociedade cabe não somente ser capaz de ler e escrever, ou seja, de significar-se, de produzir sentidos, é necessário apropriar-se dessas práticas efetivamente. Tal afirmação nos remete à necessidade de levantarmos algumas considerações sobre alfabetização e letramento.

Sabe-se que o termo letramento surgiu como uma forma de ampliar a discussão acerca da alfabetização. Muito se tem produzido sobre o assunto, por isso é necessário explicitar a posição que adotamos. Em alguns estudos, o termo letramento é empregado como "sinônimo de alfabetização, ou de técnicas relacionadas à escrita e seus usos, principalmente na escola" (TFOUNI, 2013, p. 24).

Distanciando-nos de tais afirmações, filiamo-nos àquilo que postula Tfouni (2013, p. 27) e adotamos "a concepção de letramento como fenômeno que pode atuar indiretamente, influenciando também culturas e pessoas que não dominam a escrita". Essa opção decorre do fato de que o letramento é visto como um processo mais amplo 
que a alfabetização, embora esteja intimamente relacionado ao código escrito. Dentro dessa concepção à qual nos filiamos,

A questão não se resume mais ao domínio de técnicas, habilidades, nem capacidades de uso da leitura e escrita; ela é muito mais ampla, pois nos lança o desafio de termos de descrever em que consiste o letramento dentro de uma concepção de práticas sociais que se interpenetram e se influenciam, sejam essas práticas orais ou escritas, circulem elas dentro ou fora da escola. É preciso considerar, ainda, o papel da memória (histórica e particular), além da história da constituição dos sentidos na escrita e na oralidade. (TFOUNI, 2013, p. 28)

Destacamos o seguinte fragmento na citação acima: "o letramento dentro de uma concepção de práticas sociais que se interpenetram e se influenciam, sejam essas práticas orais ou escritas, circulem elas dentro ou fora da escola". Ser letrado, portanto, não é um "privilégio" somente dos escolarizados.

Postas nossas considerações em relação à filiação com a qual optamos em trabalhar quando concebemos o termo letramento, retomemos ao papel da instituição escolar nesse processo. Sob o olhar cronológico, alfabetizador e institucional, com o qual nos contrapomos, nos primeiros anos escolares, por exemplo, a criança é levada a decodificar os símbolos utilizados para a escrita. Como a representação do cotidiano das pessoas é permeada por símbolos, codificar o pensamento por meio também da escrita é um passo que os alunos são levados a dar em direção ao processo de interpretação. Dessa maneira, a língua passa a ser considerada, de uma forma mais consciente, no mundo, consequentemente, percorrer os espaços das letras para as palavras, da união das palavras para as frases, parágrafos e finalmente chegar ao texto, são estágios que consideram o sujeito, segundo a visão institucional, seja expressando-se oralmente ou por escrito, alguém que produz sentido e usa a linguagem para interagir com a realidade social. Partindo deste raciocínio, a escola espera que além de interpretar, reconhecer e fazer uso de diversos tipos de textos, o sujeito seja capaz de colocar tais práticas em funcionamento na sociedade. É pertinente considerar que, dentro da ótica institucional escolar, observamos que interpretar é captar as ideias e intenções do autor do texto, o que nos leva a pensar a língua somente na concepção que a considera representação do pensamento e vê o sujeito como senhor absoluto de suas ações e de seu dizer. Isso nos leva a avançar para algumas discussões que consideramos fundamentais para as análises: uma delas expõe como consideramos o texto e a autoria na perspectiva discursiva, outra diz respeito a algumas considerações acerca de um discurso legitimado na sociedade brasileira que se mostra na leitura, na escrita, enfim, na sociedade e que é fruto de uma construção histórica.

\section{Texto e autoria}

No contexto proposto neste estudo, o texto é entendido como uma unidade de significação, uma unidade de análise. No entanto, é comum verificarmos nas práticas escolares e em algumas posições teóricas como a Linguística Textual e o Cognitivismo, por exemplo, que todo texto, para ser inteligível, necessita de começo, meio e fím. Além disso, sabemos que para o leitor "ingênuo", o texto 
é a unidade empírica que ele tem diante de si, feita de som, letra, imagem, sequências com uma extensão, (imaginariamente) com começo, meio e fim e que tem um autor que se representa em sua unidade, na origem do texto, "dando"-lhe coerência, progressão e finalidade. (ORLANDI, 2008, p. 64)

Todos estes aspectos somados nos levam, ainda sob esta ótica teórica, para o que tais fundamentos teóricos denominam como Unidade Textual. Fiorin (2002) teoriza, a partir dessa corrente linguística mais textual que discursiva, sendo a discursiva a que propomos em nossos estudos, que o texto não é simplesmente um amontoado de frases, mas uma unidade organizada que faz sentido. $\mathrm{O}$ autor assevera que o texto possui algumas propriedades específicas como: coerência, dois espaços de sentido (um antes de começar o texto e outro depois) e, por fim, sempre está inserido em um determinado tempo e espaço. Assim, "poderíamos dizer que um texto é, pois, um todo organizado de sentido, delimitado por dois brancos e produzido por um sujeito num dado espaço e num dado tempo" (FIORIN, 2002, p. 18). Esta noção de texto direciona tal posicionamento para duas conclusões:

a) uma leitura não pode basear-se em fragmentos isolados do texto, já que o significado das partes é determinado pelo todo em que estão encaixadas;

b) uma leitura, de um lado, não pode levar em conta o que não está no interior do texto e, de outro, deve levar em consideração a relação, assinalada, de uma forma ou de outra, por marcas textuais, que um texto estabelece com outros. (FIORIN, 2002, p. 18)

Uma vez que a leitura de um texto deve levar em conta os aspectos levantados na citação acima, acrescentamos que com a atividade de produção, dentro desta perspectiva, não é diferente, uma vez que para colocá-la em prática, o escritor também precisaria recorrer a conhecimentos que estão armazenados em sua memória cognitiva. Ainda nesta linha teórica, Koch (2012, p. 37) assevera que esses conhecimentos aos quais o escritor recorre são resultado de inúmeras atividades com as quais nos envolvemos ao longo de nossa vida e que deixam entrever a intrínseca relação entre linguagem/mundo/práticas sociais. Assim sendo, a autora relata que

A memória deixa de ser vista como um auxiliar do conhecimento, passando a ser considerada parte integrante dele, ou mesmo como a forma de todo o conhecimento: o conhecimento nada mais é que estruturas estabilizadas na memória de longo prazo, que são utilizadas para o reconhecimento, a compreensão de situações - e de textos -, a ação e a interação social. (KOCH, 2012, p. 37)

Logo, ambos os autores, Fiorin (2002) e Koch (2012), consideram que o conhecimento e a memória cognitiva nos possibilitam compreender o texto tanto em sua ordenação lógica como em sua denominada completude, ponderações estas que concebem o texto quanto à unidade linguística e das quais nos distanciamos.

Apesar de considerarmos que, na materialidade textual, os elementos internos, estruturais e linguísticos mencionados são importantes e indissociáveis entre si, entendemos que não há texto caso não haja sujeito e história. Dessa maneira, o conceito de texto com o qual comungamos propõe uma reflexão além da perspectiva linguística 
textual e perpassa pelos aspectos associados ao discurso. Tal abordagem encontra-se em Orlandi (2001), para a autora, não basta considerar o texto somente como uma unidade linguística, mas como uma unidade de sentido, portanto histórica, que por sua vez tem relação com a situação discursiva. Por seu turno,

Vamos definir diretamente o discurso como efeito de sentido entre locutores. Essa é uma definição de discurso em seu sentido amplo e nos introduz em um campo disciplinar que trata da linguagem em seu funcionamento. Ou seja, se pensamos o discurso como efeito de sentidos entre locutores, temos de pensar a linguagem de uma maneira muito particular: aquela que implica considerá-la necessariamente em relação à constituição dos sujeitos e à produção dos sentidos. Isto quer dizer que o discurso supõe um sistema significante, mas supõe também a relação deste sistema com sua exterioridade já que sem história não há sentido, ou seja, é a inscrição da história na língua que faz com que ela signifique. Daí os efeitos entre locutores. E, em contrapartida, a dimensão simbólica dos fatos. (ORLANDI, 1994, p. 53)

Dessa forma, a partir da análise da materialidade do texto, torna-se possível observar a materialidade do discurso, que implica redefinir, conforme Orlandi (2001), a materialidade linguístico-histórica. O texto é, assim, efeito de sentido e não somente unidade. Neste sentido, acrescentamos que para Orlandi

O texto atesta o modo pelo qual, pela sua função de autor, o sujeito administra a dispersão e a pressão da multiplicidade das possíveis formulações (outras) no mesmo sítio de significação. Jogo intrincado de diferentes formações discursivas, a Unidade resulta de uma construção imaginária que rege a incompletude e a dispersão real dos sujeitos e dos sentidos arregimentada pela força organizadora da ideologia, no funcionamento discursivo das relações de poder que se simbolizam. (ORLANDI, 2001, p. 97)

Ao ampliar e aprofundar o conceito de texto, compreendemos que não basta ao sujeito, por exemplo, dominar uma língua como se ela fosse transparente e finita e tê-la como pré-requisito para a efetivação da leitura e da escrita. É preciso perceber que, por ser opaca, a língua nos permite olhar para o texto como um efeito de unidade que advém de um dado funcionamento discursivo e do efeito de evidência de formações discursivas produzido pela ideologia. Isso equivale, ainda, a considerar a multiplicidade das inúmeras formulações possíveis dentro de um mesmo campo de significação. Também equivale a afirmar que há outros elementos além da coesão, da coerência e do suposto domínio da norma padrão da língua que sustentam a escrita e a leitura de um texto. Um deles é a interpretação do tex to como o efeito da ideologia, por exemplo, ideologia que consiste no "imaginário que medeia a relação do sujeito com suas condições de existência. [...] A ideologia é, pois, constitutiva da relação do mundo com a linguagem, ou melhor, ela é condição para essa relação" (ORLANDI, 1994, p. 56).

Em termos ainda mais específicos:

a ideologia é interpretação de sentidos em certa direção, determinada pela relação da linguagem com a história, em seus mecanismos imaginários. Ela não é, pois, ocultação mas função necessária entre 
linguagem e mundo. Linguagem e mundo se refletem, no sentido da refração, do efeito (imaginário) necessário de um sobre o outro. $\mathrm{Na}$ verdade, é o efeito da separação e da relação necessária mostradas no mesmo lugar. Há uma contradição entre mundo e linguagem, e a ideologia é trabalho desta contradição. (ORLANDI, 1994, p. 57)

Ver o texto como um efeito da ideologia, faz com que reconheçamos a multiciplicidade das inúmeras formulações possíveis dentro de um mesmo campo de significação, situação mais aceitável na perspectiva discursiva que textual e cognitivista, como outrora já mencionamos. Tal situação nos leva a refletir sobre a seguinte questão: é possível ser autor a partir de gestos de leitura e escrita em exames institucionalizados como o ENEM?

Para que possamos considerar um sujeito autor, a priori, é necessário compreender tal conceito a partir da perspectiva discursiva. Nesse sentido, há, para nós, no que se refere ao entendimento relativo ao conceito de autoria, um deslocamento relacionado à noção de autor comumente apresentada como aquele que produz um texto, por exemplo, e possui direitos jurídicos sobre ele. Quando Orlandi (2001) postula sobre a função autor, o faz a partir de um deslocamento em relação ao que Foucault (1969) afirmara anteriormente. Para Foucault, o autor é definido pelo próprio texto e não é visto como uma singularidade, mas como uma pluralidade, que pode dar lugar a vários egos, a várias posições-sujeitos. Assim,

a função autor está ligada ao sistema jurídico e institucional que contém, determina, articula o universo dos discursos; ela não se exerce uniformemente e da mesma maneira sobre todos os discursos, em todas as épocas e em todas as formas de civilização; ela não é definida pela atribuição espontânea de um discurso ao seu produtor, mas por uma série de operações específicas e complexas; ela não remete pura e simplesmente a um indivíduo real, ela pode dar lugar simultaneamente a vários egos, a várias posições-sujeitos que classes diferentes de indivíduos podem vir a ocupar. (FOUCAULT, 1969, p. 279)

A função autor postulada pela Análise de Discurso, por outro lado, não considera o autor como sujeito empírico, mas como posição-autor. Isso quer dizer que a posiçãoautor

corresponde ao texto como unidade significativa em relação à situação: a imprensa (em que se desloca a relação causa/efeito), o contexto (situação: representada no imaginário da separação objetivo/subjetivo), os sujeitos (onde trabalha a relação imaginária entre exterior/interior). O pessoal polimorfo cede seu lugar ao imutável público e múltiplo. Nos termos discursivos [...], o autor é posição-autor e não autor empírico: é um lugar, no imaginário, constituído pelo confronto do simbólico com o político. (ORLANDI, 2001, p. 80)

Enquanto para Foucault a autoria se constitui no centro da noção de texto que se torna "obra de", para Orlandi o texto se constitui a partir de uma associação entre o simbólico, o contexto e os sujeitos. Visto dessa maneira, o texto é considerado não somente em seu aspecto simbólico, linguístico e político, mas como uma materialidade que permite observar a materialidade do discurso. 
Ademais, torna-se, pois, necessário considerar que, na perspectiva da $\mathrm{AD}$, colocar-se na posição de autor requer do sujeito que ele conheça não somente como uma língua se estrutura, se combina no nível frasal e textual, pois isso não bastaria. Para se posicionar enquanto autor daquilo que lê e escreve, é preciso evocar a memória discursiva, que segundo Pêcheux,

Seria aquilo que, em face de um texto que surge como acontecimento a ler, vem restabelecer os 'implícitos' (quer dizer, mais tecnicamente, os pré-construídos, elementos citados e relatados, discursos transversos, etc.) de que sua leitura necessita: a condição do legível em relação ao próprio legível”. (PÊCHEUX, 1999, p. 52)

Ressaltamos que "acontecimento" na teoria pchethiana institui a independência do objeto discursivo face a qualquer acontecimento datado. Assim, se um texto surge como acontecimento, tal consideração implica em delinear a noção de texto discursivamente. Dessa forma,

o texto não pode assim ser visto como uma unidade fechada pois ele tem relação com outros textos (existentes, possíveis ou imaginários), com suas condições de produção (os sujeitos e a situação) e com o que chamamos exterioridade constitutiva, ou seja, o interdiscurso, a memória do dizer (o que fala antes, em outro lugar, independentemente). (ORLANDI, 2001, p. 87)

Por isso, voltemos à noção já naturalizada de texto como unidade, que prega que todo texto deve ter começo, meio e fim e reformulemos da seguinte maneira: "se, enquanto unidade empírica, o texto é uma unidade com limites - começo, meio, progresso e fim - e, enquanto unidade imaginária, ele também se representa em sua unidade organizada, enquanto unidade discursiva é uma unidade aberta" (ORLANDI, 2001, p. 90). Por ser considerado desta maneira, em todo texto

há uma injunção à textualidade na linguagem e não há texto sem autor. Há função-autor desde que haja um sujeito que se coloca na origem do dizer, produzindo o efeito de coerência, não contradição, progressão e fim. Para mim, a autoria é uma injunção do dizer assim como o é a interpretação: face ao sujeito, todo objeto simbólico deve produzir sentido. Do mesmo modo, para significar estamos sempre interpretando, mesmo sem o reconhecer, e "assinamos" embaixo de "nossas" palavras, assim nos constituímos autores de nossos textos. A produção imaginária da unidade é um dos efeitos dos mais importantes da função-autor, tal como a penso no ordinário do discurso, no cotidiano das palavras. Tanto para a oralidade como para a escrita. A relação é pois autor/texto e não autor/obra. (ORLANDI, 2001, p. 91)

Assim, é possível encontrar a função-autor em exames como o ENEM, desde que este texto seja produzido com efeito de coerência, não contradição, progressão e fim. $\mathrm{O}$ texto mostra, portanto,

como se organiza a discursividade, isto é, como o sujeito está posto, como ele está significando sua posição, como a partir de suas condições (circunstâncias da enunciação e memória) ele está praticando a relação 
do mundo com o simbólico, materializando sentido, textualizando, formulando. (ORLANDI, 2008, p. 67)

Consequentemente, parafraseando Orlandi (2008), não é no texto que estão as inúmeras possibilidades de leitura e sim no espaço constituído pela relação do discurso e do texto. Da organização sujeito-língua-história, sujeito-autor, discurso-texto, surge o eixo organização-textualização-autoria. O resultado de toda essa articulação é o que chamamos efeito-leitor, que configura a prática específica da leitura.

Por nos interessar mais a questão relativa a autor/texto e não autor/obra é que concebemos a Análise de Discurso justificável quando, parafraseando Gallo (1991), partiremos do texto para refazer a trajetória do sujeito que o produziu, através das pistas que o texto oferece, passando necessariamente pelas condições de produção deste texto, para retornar ao texto e finalmente compreendê-lo. Disso emerge a efetivação o efeito leitor, que segundo a mesma autora, ocorre quando o sujeito se constitui na formação discursiva dominante de um discurso legitimado. Tal discurso legitimado é, por sua vez, fruto histórico, como veremos no capítulo seguinte.

\section{A legitimação de um discurso na história brasileira}

A legitimação do discurso é, necessariamente, uma construção histórica. Silva (1998), por exemplo, retoma a história da leitura e da escrita no Brasil, tomando como referência as políticas e as práticas linguísticas e pedagógicas de leitura e de escrita dos séculos iniciais da colonização. A autora traz como tema a história da alfabetização, a fim de compreender como este sujeito constituído na e pela linguagem constrói a história da leitura e da escrita de um país colonizado. Além de fazer uma leitura do discurso das Ciências Sociais e Humanas em que "alfabetização-analfabetismo", "alfabetizadoanalfabeto", enquanto oposições construídas historicamente, aparecem - ou não - como objetos referidos por uma posição de sujeito, a referida autora também analisa esse processo de produção de conhecimento das Ciências Sociais e Humanas - um processo de leitura e de escrita. Com isso, a autora foi capaz de perceber a

Dimensão histórica de uma posição de sujeito: a de quem fala e é falado do lugar de alfabetizado, de quem ingressou em uma sociedade letrada, de quem assumiu a função de autoria e pode falar do outro, o analfabeto: que só podia aí existir no discurso como objeto referido. (SILVA, 1998, p. 14)

Ao observarmos o termo "outro", remetemo-nos à questão da identidade, que, segundo Orlandi (2013, p 46) é movimento, "tanto no seu modo de funcionamento (entre o eu e o outro) como em sua historicidade (devir, mas, também, multiplicidade na contemperaneidade etc.)". Dessa maneira, o que verificamos é que

O europeu nos constrói como seu "outro" mas, ao mesmo tempo, nos apaga. Somos o "outro", mas o outro "excluído", sem semelhança interna. Por sua vez, eles nunca se colocam na posição de serem "outro". Eles são sempre o "centro", dado o discurso das des-cobertas que é um discurso sem reversibilidade. Nós é que os temos como nossos "outros" absolutos. (ORLANDI, 2013, p 47, grifos da autora) 
Assim, para compreender o processo de constituição dos sentidos e do sujeito da escolarização no Brasil, é preciso compreender as políticas e as práticas linguísticas e pedagógicas de leitura e de escrita dos séculos iniciais da colonização. Por esse processo, torna-se possível entender um pouco mais a história da leitura e da escrita de um país colonizado. É, pois, no confronto do discurso científico e do discurso religioso, que Silva constrói um arquivo em que filiações discursivas de escrita alfabética vão adquirindo visibilidade em uma memória coletiva. Assim, percebe-se a

Relação existente entre o funcionamento de uma função do sujeito - a de autoria - em diferentes áreas do conhecimento, qual seja a de ser a origem do seu dizer e responsável por esse mesmo dizer, e a posição de sujeito escolarizado em que a dicotomia alfabetizado - analfabeto significa, atua, funciona. (SILVA, 1998, p. 14)

Cremos que essa dimensão história retratada e retomada por Silva, permite-nos considerar que é, no mínimo, uma ingenuidade visualizar um sistema educacional hoje cuja questão histórica em relação aos aspectos ligados à apropriação da língua não seja levada em consideração. Há uma dinâmica considerável em parte de todo processo educacional atual que, inevitavelmente, lança mão de uma memória que traz à tona, constantemente, o que outrora já fora posto e ao passar pelas condições de produção de qualquer texto, intrinsecamente estamos atrelados a um passado de nação, por exemplo, colonizada, cuja história é ditada e escrita por cabeças que não compunham a base da sociedade, mas o topo da pirâmide, portanto, era escrita por quem estava no alto a olhar a massa analfabeta, ignorante e desqualificada intelectualmente.

A partir dos estudos realizados por Silva (1998) verificaremos, por exemplo, que durante todo o processo de colonizado pelo qual passou o povo brasileiro, é possível observar, basicamente, cinco tipos de discursos nos registros históricos: o da cultura, o da história da literatura, o da história, o da sociologia e o discurso da religião. Eles nos permitem identificar aquilo que ficou na memória do dizer, que funciona, mas que não se mostra ao enunciador. Podemos observar, por exemplo, como os brasileiros letrados leem e escrevem a partir dessa memória e que posição é reservada aos não letrados dentro desta dinâmica diacrônica. Investigar os processos de leitura e de escrita nos possibilitam dentre outras coisas, observar os discursos provenientes de variados textos, sob variadas perspectivas.

O que observamos é que passamos por um processo de rememoração, constituímo-nos como povo submisso, à espera da próxima ordem, exatamente como hoje socialmente nos organizamos. Ressaltamos que diante do processo histórico pelo qual percorremos, somos um povo obediente a um português que manda. Nesta conjuntura não havia, pois, lugar para a educação, para a escola e muito menos para um aprendizado de leitura e escrita, afinal, caso isso se instalasse, seria correr um risco de o colonizador perder o poder da submissão imposta ao colonizado. Hoje há este espaço existe, mas a constituição de escola detentora do conhecimento versus aluno que põe em prática este conhecimento ainda se estabelece e nos traz constantemente à tona nossas origens submissas.

Dessa forma, acreditamos que ao analisar a proposta de redação do ENEM de 2014 e a produção textual de um candidato, temos a oportunidade de observar como o candidato tenta aderir ao discurso já posto e legitimado, como ele o compreende, qual sua 
posição sujeito ao formular seu texto. E, também, buscamos compreender como este sujeito se coloca na função autor ao produzir seu texto. Antes, no entanto, pretendemos descrever as reformulações pelas quais o Exame passou desde seu surgimento, a fim de contextualizarmos nossas análises.

\section{ENEM: contextualização e principais reformulações}

Em 2012, o governo federal elaborou "A redação no Enem 2012 - Guia do participante", um material oferecido pela primeira vez ao candidato, desde a implantação do exame em 1998. Com o intuito de transmitir "tranquilidade, desde a inscrição até o momento do Exame e da divulgação dos resultados", o objetivo do Guia é tornar "o mais transparente possível a metodologia de correção da redação, bem como o que se espera do participante em cada uma das competências avaliadas" (MINISTÉRIO DA EDUCAÇÃO, 2012, p. 5). Chamamos atenção para o termo "transparente". O documento em questão toma como pressuposto, quando usa esse termo, que existe transparência tanto na linguagem quanto nas práticas avaliativas, situação que contestamos uma vez que na perspectiva discursiva, concebe-se que a língua é justamente o oposto do que se coloca como transparente, ela é opaca, passível de outras interpretações. Dizer que se pretende tornar o mais transparente possível o método de correção da redação é conceber, como a instituição escola faz, um sujeito idealizado, quando sabemos que o sujeito é determinado ideologicamente, historicamente etc.. Dessa forma, parafraseando Orlandi (1994), não há relação direta, ou transparente da linguagem com o mundo, o que há é uma relação que funciona como tal por causa do imaginário. Vejamos um exemplo: ainda em 2012, e nos anos sequentes, além do Guia do Participante, “o Inep apresentou a vista pedagógica das redações, que permitiu ao participante a visualização da sua redação com informações da avaliação por competência, possibilitando reflexão pedagógica mais aprofundada sobre seu desempenho." (MINISTÉRIO DA EDUCAÇÃO, 2013, p. 3). Em 2013, a versão do Guia foi atualizada, com o objetivo de agregar informações para auxiliar nos estudos e na preparação do candidato para o Exame. A atualização ocorreu especialmente no item que apresenta o tema do ano anterior e as redações de candidatos, bem como a avalição delas. Essa reformulação tem sido constante desde 2012. O guia, dessa forma, "busca esclarecer os critérios adotados no processo de avaliação das redações do Enem, responder às principais dúvidas dos participantes e mostrar exemplos de redações que obtiveram nota máxima.” (MINISTÉRIO DA EDUCAÇÃO, 2013, p. 3).

Ora, pensando a estrutura - no caso, o ENEM - como o repetível e o acontecimento - no caso, a disponibilização da correção da redação - como o deslocamento que inaugura o novo, é possível afirmar que o discurso é simultaneamente estrutura e acontecimento. Não que a verdade esteja no acontecimento, o que buscamos entender é como esse acontecimento se constitui, pois acreditamos que o ENEM sempre teve em seu imaginário o aluno ideal, afinal toda prática avaliativa, todo processo seletivo parte de um imaginário de aluno ideal. O "aluno ideal" é assim aquele regulado pela língua, submetido aos critérios e individuado pelo Estado, tendo como instituição reguladora o INEP. A escola, por sua vez é um lugar de controle, assim como é o Estado, dessa forma, oferecer uma vista pedagógica da redação somente 14 anos depois do processo ter se iniciado não é algo desconectado, é uma estratégia metalinguística, mais uma forma de usar a língua para apresentar como deve ser esse candidato regulado pela própria língua na escola. Em 
outras palavras, o ENEM é também uma prática avaliativa tal qual a que se reproduz na escola.

Dessa forma, oferecer uma vista pedagógica da redação somente 14 anos depois do processo ter se iniciado não é algo desconectado. Quando afirmamos isso, reportamonos a Orlandi (2003, p.7), "Não se trata, pois das ideias estarem fora do lugar. O fato é que na constituição dos sentidos elas podem sofrer um deslizamento, um processo de transferência que faz com que apareçam como deslocadas". Assim, sempre incompleto, o dizer continua em seus movimentos de significação, deixando que a memória, a opacidade e os equívocos, o trabalhem como acontecimento discursivo, indefinidamente (ORLANDI, 2002).

Consequentemente, nesta relação de discursos que se cruzam com outros discursos, desde seu surgimento, o ENEM passou por algumas reformulações, que incluem, em uma delas, a disponibilização do material que mencionamos (O Guia e o espelho da produção de texto do candidato). Todas as modificações ocorridas desde seu surgimento até o atual momento só reforçam nossa reflexão de que o ENEM não tem um controle total e planejado do processo, pelo contrário, quando as situações envolvem sujeitos não há controle. Comungamos com o que assevera Orlandi (2003), quando a autora diz que "não há controle 'pessoal' ou 'coletivo' dos processos e da história dos quais sujeitos e sentidos participam. O que há é a aparência de controle e de certeza dos sentidos porque as práticas sócio-históricas são regidas pelo imaginário, que é político.” (ORLANDI, 2003, p. 7).

Quando dizemos que o ENEM passou por algumas reformulações, não afirmamos, porém, que isso é claramente posto. Inclusive, no site do INEP, na sessão sobre o ENEM, não encontramos formulações diretas que se refiram a essas reformulações, conforme podemos verificar:

O Exame Nacional do Ensino Médio (Enem) foi criado em 1998 com o objetivo de avaliar o desempenho do estudante ao fim da educação básica, buscando contribuir para a melhoria da qualidade desse nível de escolaridade. A partir de 2009 passou a ser utilizado também como mecanismo de seleção para o ingresso no ensino superior. Foram implementadas mudanças no Exame que contribuem para a democratização das oportunidades de acesso às vagas oferecidas por Instituições Federais de Ensino Superior (IFES), para a mobilidade acadêmica e para induzir a reestruturação dos currículos do ensino médio. Respeitando a autonomia das universidades, a utilização dos resultados do Enem para acesso ao ensino superior pode ocorrer como fase única de seleção ou combinado com seus processos seletivos próprios. O Enem também é utilizado para o acesso a programas oferecidos pelo Governo Federal, tais como o Programa Universidade para Todos - ProUni. (INEP, 2015)

Apesar de o documento acima não reportar às reformulações, o trecho "A partir de 2009 passou a ser utilizado... Foram implementadas mudanças no Exame..." é indiciado por verbos e dêiticos que levam a entender que o processo, em algum momento, no caso a partir de 2009, sofreu alterações. No entanto, de acordo com Santos (2011), essas reformulações ocorreram pelo menos em 3 (três) momentos. A primeira delas aconteceu entre os anos de 1998 a 2003, neste momento, o Exame tinha como objetivo 
avaliar o ensino médio brasileiro, dessa forma, somente algumas instituições federais é que abrem a possibilidade de acesso ao ensino superior por esse sistema. Já na segunda reformulação, que se refere ao período de 2004 a 2008, o ENEM passa a funcionar como instrumento seletivo. Além disso, o Estado passa a conceder bolsas parciais e integrais em IES privadas, através do ProUni ${ }^{3}$. Em 2009, o Exame é denominado com a reformulação "Novo Enem" (Portaria no 109, de 27 de maio de 2009), há, nesta fase, mudanças tanto nos objetivos como na estrutura organizacional da prova. A Portaria, afirma, assim, as seguintes fundamentações:
Artigo $1^{\circ}$ - Instituir o Exame Nacional do Ensino Médio - ENEM, como procedimento de avaliação do desempenho do aluno, tendo por objetivos:
I - conferir ao cidadão parâmetro para autoavaliação, com vistas à continuidade de sua formação e à sua inserção no mercado de trabalho; II - criar referência nacional para os egressos de qualquer das modalidades do ensino médio;
III - fornecer subsídios às diferentes modalidades de acesso à Educação superior (Portaria MEC nº 438, de 28 de maio de 1998).

Nesta $3^{\text {a }}$ reformulação de consolidação do Exame surgiram dois episódios que até o momento não tinham ocorrido: em 2009 o MEC cancelou a prova por suspeita de fraude $^{4}$ e remarcou a data de aplicação do Exame. Já no ano seguinte, cadernos de prova amarelos apresentaram problemas de impressão e montagem. Alguns participantes tiveram seus cadernos substituídos, outros não, assim a prova teve que ser reaplicada ${ }^{5}$. Importa-nos salientar que esses dois episódios são simultâneos à consolidação do Exame e não por acaso, alguns conflitos são produzidos, isso, justamente pelo fato de que as posições que os sujeitos ocupam nem sempre são as mesmas. Enquanto de um lado há a consolidação do Exame e um discurso de democratização do ensino, pois em alguns discursos o ENEM é significado como processo seletivo capaz de avaliar, por outro lado há discursos que defendem ser o ENEM uma política seletiva que fere os direitos da autonomia das universidades, além de impedir que elas obtenham recursos financeiros com o vestibular.

Parafraseando Orlandi (2008), o político, no sentido proposto aqui, é visto como um ponto de vista discursivo que é definido pelo fato de que o sentido é sempre dividido, por sua vez, "esta divisão tendo uma direção que não é indiferente às injunções que derivam da forma da sociedade tomada na história em um mundo significado e significante, em que as relações de poder são simbolizadas" (ORLANDI, 2008, p. 90). Assim, os conflitos são gerados tendo de um lado posições sujeito a favor do Exame, por outro lado, posições sujeitos contrárias. Pensando sob o ponto de vista pecheutiano, tratase

de pensar por um lado o discurso como uma materialidade igualmente constituída por uma estrutura e por um acontecimento e, por outro, que esse estruturamento discursivo se dá sempre não na estabilidade da

\footnotetext{
${ }^{3}$ Criado pelo Governo Federal em 2004 e institucionalizado pela Lei no 11.096, em 13 de janeiro de 2005 oferece, em contrapartida, isenção de tributos àquelas instituições que aderem ao Programa. [cf.] em http://prouniportal.mec.gov.br/o-programa. Acesso em 17/02/2017.

${ }^{4}$ Cf. em: http://educacao.uol.com.br/ultnot/2009/10/01/ult105u8763.jhtm.

5 Cf. em: http://educacao.uol.com.br/noticias/2010/12/15/prova-para-prejudicados-no-enem-2010-ereaplicada-nesta-quarta.htm.
} 
veiculação de valores ideológicos, mas, principalmente, na instabilidade produzida pela tensão, pelo conflito, pelo contínuo atravessamento de/entre esses valores. (BARONAS; AGUIAR, 2009, p. 167)

Concebemos, ainda, que disponibilizar o Manual e a vista pedagógica é uma maneira que o sistema encontrou de cumprir de forma mais prática o inciso II da Portaria $n^{\circ} 438$, já mencionada: "conferir ao cidadão parâmetro para autoavaliação, com vistas à continuidade de sua formação e à sua inserção no mercado de trabalho", além de tentar estabilizar possíveis tensões de cunho político, como por exemplo, evitar que fossem levantadas dúvidas sobre a seriedade e sigilo das correções por aqueles não tão favoráveis ao ENEM. Dessa maneira, não consideramos que foram somente três reformulações como afirma Santos (2011), acrescentamos que, para nós, a partir de 2012, o Exame pode ser inserido no que observamos como $4^{\text {a }}$ reformulação. As propostas de Redação, deste momento, tornam-se estruturalmente semelhantes - como é possível verificar nas figuras abaixo -, principalmente quanto às instruções que seguirão a seguinte padronização: indicação de que o texto deve ser produzido a partir da leitura dos textos motivadores e dos conhecimentos que o candidato adquiriu ao longo de sua formação, referência quanto à redação de um texto dissertativo-argumentativo e em norma padrão da língua portuguesa, especificação do tema, apresentação explícita da Competência V (Elaborar proposta de intervenção para o problema abordado, respeitando os direitos humanos) e da obrigatoriedade em respeitar os direitos humanos ao propor a proposta de intervenção e, por fim, ordenação quanto aos aspectos organizacionais do texto a partir dos verbos de comando selecionar, organizar e relacionar. Vejamos:

A partir da leitura dos textos motivadores seguintes e com base nos conhecimentos construídos ao longo de sua formação, redija texto dissertativo-argumentativo em norma padrāo da língua portuguesa sobre o tema O MOVIMENTO IMIGRATORIO PARA O BRASIL NO SÉCULO XXI, apresentando proposta de intervenção, que respeite os direitos humanos. Selecione, organize e relacione, de forma coerente e coesa, argumentos e fatos para defesa de seu ponto de vista.

Figura 1 - Tema de redação ENEM 2012.

A partir da leitura dos textos motivadores seguintes e com base nos conhecimentos construídos ao longo de sua formação, redija texto dissertativo-argumentativo na modalidade escrita formal da língua portuguesa sobre o tema "Efeitos da implantação da Lei Seca no Brasil", apresentando proposta de intervençāo, que respeite os direitos humanos. Selecione, organize e relacione, de forma coerente e coesa, argumentos e fatos para defesa de seu ponto de vista.

Figura 2 - Tema de redação ENEM 2013.

A partir da leitura dos textos motivadores seguintes e com base nos conhecimentos construidos ao longo de sua formação, redija texto dissertativo-argumentativo em norma padrão da língua portuguesa sobre o tema Publicidade infantil em questão no Brasil, apresentando proposta de intervenção, que respeite os direitos humanos. Selecione, organize e relacione, de forma coerente e coesa, argumentos e fatos para defesa de seu ponto de vista.

Figura 3 - Tema de redação ENEM 2014.

A partir da leitura dos textos motivadores seguintes e com base nos conhecimentos construidos ao longo de sua formação, redija texto dissertativo-argumentativo em modalidade escrita formal da língua portuguesa sobre o tema "A persistência da violência contra a mulher na sociedade brasileira", apresentando proposta de intervenção que respeite os direitos humanos. Selecione, organize e relacione, de forma coerente e coesa, argumentos e fatos para defesa de seu ponto de vista.

Figura 4 - Tema de redação ENEM 2015. 
A partir da leitura dos textos motivadores e com base nos conhecimentos construidos ao longo de sua formação, redija texto dissertativo-argumentativo em modalidade escrita formal da lingua portuguesa sobre o tema "Caminhos para combater a intolerância religiosa no Brasil", apresentando proposta de intervençāo que respeite os direitos humanos. Selecione, organize e relacione, de forma coerente e coesa, argumentos e fatos para defesa de seu ponto de vista.

Figura 5 - Tema de redação ENEM 2016.

Observamos, ainda, que além da padronização do enunciado da redação, houve, nesta $4^{\mathrm{a}}$ fase, a cobrança mais explícita da competência V (Elaborar proposta de intervenção para o problema abordado, respeitando os direitos humanos), conforme destaca o enunciado "apresentando proposta de intervenção". Essa cobrança nem sempre ocorreu de forma tão evidente, como podemos verificar no excerto abaixo relativo à proposta de redação do primeiro ano (1998) do exame.

Redija um texto dissertativo, sobre o tema "Viver e Aprender", no qual você exponha suas idéias de forma clara, coerente e em conformidade com a norma culta da língua, sem se remeter a nenhuma expressão do texto motivador "O Que É O Que É".

Dê um título à sua redação, que deverá ser apresentada a tinta e desenvolvida na folha anexa ao Cartão-Resposta. Você poderá utilizar a última página deste Caderno de Questões para rascunho.

\title{
Figura 6 - Tema de redação ENEM 1998.
}

Já em outros anos, quando a "proposta de intervenção" foi posta de maneira explícita nas Proposta de redação, houve variação em relação à forma como foi solicitada, conforme podemos verificar, por exemplo, nas propostas dos anos de 1999 e 2000.

\footnotetext{
Com base na leitura dos quadrinhos e depoimentos, redija um texto em prosa, do tipo dissertativo-argumentativo, sobre o tema: Cidadania e participacão social.

Ao desenvolver o tema proposto, procure utilizar os conhecimentos adquiridos ao longo de sua formaçăo. Depois de selecionar, organizar e relacionar os argumentos, fatos e opiniōes apresentados em defesa de seu ponto de vista, elabore uma proposta de açăo social.

A redaçăo deverá ser apresentada a tinta na cor azul ou preta e desenvolvida na folha grampeada ao Cartăo-Resposta. Você poderá utilizar a última página deste Caderno de Questőes para rascunho.
}

\section{Figura 7 - Tema de redação ENEM 1999.}

\begin{abstract}
Com base na leitura da charge, do artigo da Constituição, do depoimento de A.J. e do trecho do livro 0 cidadão de papel, redija um texto em prosa, do tipo dissertativo-argumentativo, sobre o tema: Direitos da criança e do adolescente: como enfrentar esse desafio nacional?
\end{abstract}

Ao desenvolver o tema proposto, procure utilizar os conhecimentos adquiridos e as reflexões feitas ao longo de sua formação. Selecione, organize e relacione argumentos, fatos e opiniões para defender o seu ponto de vista, elaborando propostas para a solução do problema discutido em seu texto.

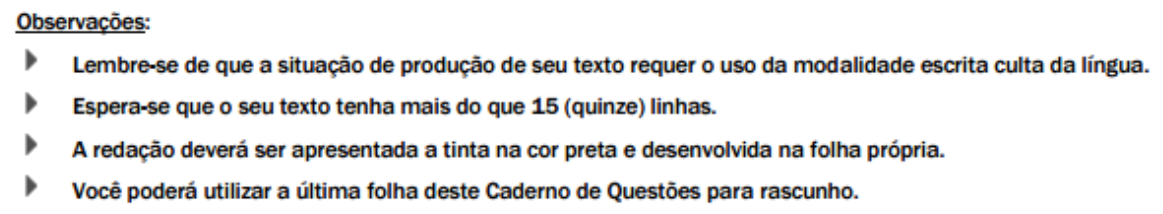

Figura 8 - Tema de redação ENEM 2000.

É possível observar que além das instruções organizadas semelhantemente a partir $4^{\mathrm{a}}$ reformulação, todos os critérios avaliativos, portanto, todas as competências exigidas na produção de texto são explicitadas diante da vista pedagógica a qual o candidato tem acesso pelo site do Inep. Segundo o site, essa "transparência" é importante, pois "Os itens formulados pelos colaboradores do ENEM estruturam-se a partir de uma matriz de 
competências e habilidades que corresponde às possibilidades totais de cognição humana na fase de desenvolvimento próprio aos participantes do ENEM" (INEP, 1999, p. 9). A reflexão que propomos é: o que o documento entende como competências e habilidades? A partir da leitura deste documento governamental, encontramos a seguinte definição:

Competências são as modalidades estruturais da inteligência, ou melhor: ações e operações que utilizamos para estabelecer relações com e entre objetos, situações, fenômenos e pessoas que desejamos conhecer. As habilidades decorrem das competências adquiridas e referem-se ao plano imediato do 'saber fazer'. Por meio das ações e operações, as habilidades aperfeiçoam-se e articulam-se, possibilitando nova reorganização das competências. (INEP, 1999, p. 7)

Segundo o documento, as habilidades procedem das competências adquiridas e ambas se diferenciam senão pelo contexto, ou melhor, pelas situações inúmeras pelas quais qualquer um está sujeito a passar. Dessa forma, constatamos o que já mencionamos no capítulo I sobre o papel da escola, que desenvolve práticas de letramento, por exemplo, como se fossem sempre práticas de leitura/escrita de textos, característica de situações que estão pautadas em processos ligados à alfabetização, codificação, cognição. A mesma perspectiva parece fundamentar e direcionar práticas avaliativas como o ENEM, que também considera que competências e habilidades se complementam, logo, a partir dessa confluência, espera-se que o candidato seja capaz de usar de competências e habilidades desenvolvidas na escola para que proponha intervenções sociais que respondam às expectativas da banca e que o coloquem no lugar de sujeito participante, integrante, social, cidadão. A prova de redação, por sua vez, é um momento de se avaliar como essas competências foram postas pela escola, conforme lê-se:

a prova de redação exigirá de você a produção de um texto em prosa, do tipo dissertativo-argumentativo, sobre um tema de ordem social, científica, cultural ou política. Os aspectos a serem avaliados relacionam-se às "competências" que devem ter sido desenvolvidas durante os anos de escolaridade. (MINISTÉRIO DA EDUCAÇÃO, 2013, p. 07)

Como se pode observar no trecho, os temas propostos possuem cunho social, científico, cultural ou político, instâncias nas quais qualquer cidadão está inserido, justamente por viver em sociedade. Passemos, pois, à análise da proposta de redação do ENEM de 2014, bem como da produção textual mobilizada por essa proposta.

\section{Análises}

Como já afirmamos, as propostas de redação do ENEM, especialmente a partir de 2012, tornam-se estruturalmente semelhantes quanto aos aspectos injuntivos, conforme já mencionamos no segundo tópico. Após o título "Proposta de Redação", observa-se que os comandos são os seguintes: ler os textos motivadores, ter como base os conhecimentos construídos ao longo da formação, redigir um texto dissertativo-argumentativo em norma padrão da língua portuguesa, levar em conta o tema proposto, apresentar proposta de intervenção que não fira os direitos humanos, selecionar, organizar e relacionar os argumentos de forma coerente e coesa em defesa de um ponto de vista. 

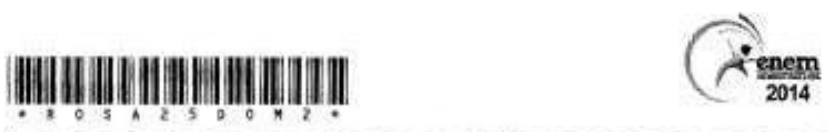

\section{PROPOSTA DE REDAÇÃO}

A partir da leitura dos textos motivadores seguintes e com base nos conhecimentos construídos ao longo de sua formação, redija texto dissertativo-argumentativo em norma padrão da lingua portuguesa sobre o tema Publicidade infantil em questão no Brasil, apresentando proposta de intervenção, que respeite os direitos humanos. Selecione, organize e relacione, de forma coerente e coesa, argumentos e fatos para defesa de seu ponto de vista.

\section{TEXTO I}

A aprovaçăo, em abril de 2014 , de uma resolução que considera abusiva a publicidade infantil, emitida pelo Conselho Nacional de Direitos da Criança e do Adolescente (Conanda), deu inicio a um verdadeiro cabo de guerra envolvendo ONGs de defesa dos direitos das crianças e setores interessados na continuidade das propagandas dirigidas a esse público.

Elogiada por pais, ativistas e entidades, a resoluçăo estabelece como abusiva toda propaganda dirigida à criança que tem "a intenção de persuadi-la para o consumo de qualquer produto ou serviço" e que utilize aspectos como desenhos animados, bonecos, linguagem infantil, trilhas sonoras com temas infantis, oferta de prêmios, brindes ou artigos colecionáveis que tenham apelo às crianças.

Ainda há dúvidas, porém, sobre como será a aplicaçăo prática da resoluçăo. E associaçōes de anunciantes, emissoras, revistas e de empresas de licenciamento e fabricantes de produtos infantis criticam a medida e dizem năo reconhecer a legitimidade constitucional do Conanda para legislar sobre publicidade e para impor a resolução tanto às familias quanto ao mercado publicitário. Além disso, defendem que a autorregulamentaçăo pelo Conselho Nacional de Autorregulamentaçāo Publicitária (Conar) já seria uma forma de controlar e evitar abusos.

TEXTO II

IDOETA, P. A: BARBA, M. D. A publicidade infantil deve ser proibida? Oisponivol em: uwwibbo co uk. Acesso em: 23 maio 2014 (adaptaba).

\section{A PUBLICIDADE PARA CRIANÇAS NO MUNDO}

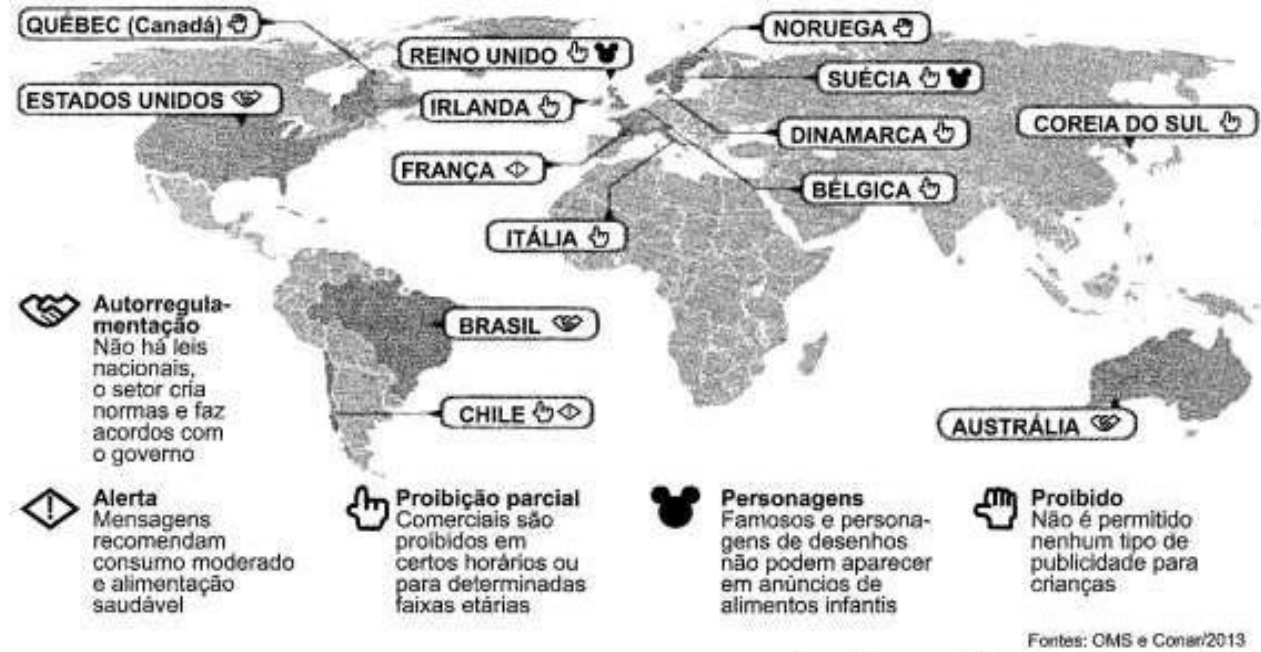

TEXTO III

Disponivel em; www1. fohtra .uol.com. br. Aceseso em: 24 jun. 2014 (edeptedo).

Precisamos preparar a criança, desde pequena, para receber as informaçōes do mundo exterior, para compreender o que está por trás da divulgaçāo de produtos. Só assim ela se tornará o consumidor do futuro, aquele capaz de saber o que, como e por que comprar, ciente de suas reais necessidades e consciente de suas responsabilidades consigo mesma e com o mundo.

SALVA, A, M. D. VASCONCELOS, L R. A criança o o markoting intocmaçhes essenciais para protoges as criangas dos apelos do marketing infanel. Säo Paulo: Summus, 2012 (adaptedo).

\section{INSTRUÇÕES:}

- O rascunho da redaçäo deve ser feito no espaço apropriado.

- O texto definitivo deve ser escrito à tinta, na folha própria, em até 30 linhas.

- A redaçāo que apresentar cópia dos textos da Proposta de Redação ou do Caderno de Questōes terá o número de linhas copiadas desconsiderado para efeito de correção.

Receberá nota zero, em qualquer das situaçōes expressas a seguir, a redação que:

- tiver até 7 (sete) linhas escritas, sendo considerada "insuficiente".

- fugir ao tema ou que nāo atender ao tipo dissertativo-argumentativo.

- apresentar proposta de intervençăo que desrespeite os direitos humanos.

- apresentar parte do texto deliberadamente desconectada com o tema proposto.

LC - $2^{\circ}$ dia | Caderno 8 - ROSA - Página 2

Figura 9 - Tema de redação ENEM 2014. 
Como é possível observar na Proposta de Redação de 2014, ler o excerto requer compreender e interpretar os textos verbais e não verbais, que na referida Proposta trouxe o Texto I e o Texto III em forma verbal e o Texto II em forma não verbal.

Ter como base os conhecimentos adquiridos ao longo da formação instrui o candidato a buscar, segundo lemos no guia, em sua memória cognitiva, aquilo que apreendeu durante os anos escolares e que contribuirá para o desenvolvimento da proposta, ou seja, é o mesmo que retomar a concepção de conhecimento repositório, cumulativo, memorizável. Nesta conjuntura memorizável, torna-se fundamental ao candidato redigir um texto dissertativo-argumentativo que inclui, pois, ter um ponto de vista diante de um tema e tecer estratégias argumentativas que convençam o leitor sobre tal, isso quer dizer selecionar, organizar e relacionar tais argumentos de maneira coesa e coerente, e, por fim, apresentar proposta de intervenção que não fira os direitos humanos. Em relação a esta última instrução supõe-se que para apresentar proposta de intervenção, o sujeito precisa levantar problemas relativos ao tema e, consequentemente, discuti-los durante o texto e finalmente conhecer os direitos humanos a fim de não ferir seus princípios ao apresentar possíveis soluções para os problemas discutidos. Atender aos aspectos instrucionais, é, dessa forma, uma das primeiras maneiras de colocar-se na função-autor em relação à tarefa de redigir um texto em que se responda às demandas exigidas pelo Exame. Nesse prisma, ao atender o que a prova propõe e solicita, o candidato estaria apenas retomando já-ditos e discursos legitimados em nosso contexto sócio-histórico? Há, portanto, um jogo discursivo em funcionamento; nele, o alunocandidato deve seguir as regras propostas para sair bem na avaliação. O próprio Guia do Participante deixa evidente o que considera como autoria:

o participante seleciona, organiza e relaciona informações, fatos, opiniões e argumentos pertinentes ao tema proposto de forma consistente, configurando autoria, em defesa de seu ponto de vista. Explicita a tese, seleciona argumentos que possam comprová-la e elabora conclusão ou proposta que mantenha coerência com a opinião defendida na redação. (MINISTÉRIO DA EDUCAÇÃO, 2012, p. 21, grifo nosso)

Destacamos o termo "autoria", no recorte acima, por nos parecer uma exigência, no mínimo, contraditória, já que questionamos até que ponto um candidato, após atender às prescrições da proposta de redação que já o direciona para um sítio de significação e para interpretações autorizadas e não autorizadas nessa prática avaliativa teria condições de "configurar sua autoria" de alguma forma? Na perspectiva discursiva, ao significar, o sujeito interpreta e se constitui autor. Isso ocorre, porque, parafraseando Orlandi (2008), a autoria é uma injunção do dizer uma vez que face ao sujeito, todo objeto simbólico deve produzir sentido. Outra "oportunidade" que o candidato parece ter oportunidade de se colocar como autor, no Exame, é no momento em que precisa apresentar proposta de intervenção, avaliada especificamente quando é analisada a Competência V, vejamos:

O quinto aspecto a ser avaliado no seu texto é a apresentação de uma proposta de intervenção para o problema abordado. Assim, a sua redação, além de apresentar sua tese sobre o tema, apoiado em argumentos consistentes, precisará oferecer uma proposta de intervenção na vida social. Essa proposta, ou seja, a solução para o problema, deve contemplar cada ponto abordado na argumentação. Assim, a proposta deve manter um vínculo direto com a tese 
desenvolvida no texto e manter coerência com os argumentos utilizados, já que expressa a sua visão, como autor, das possíveis soluções para a questão discutida. (MINISTÉRIO DA EDUCAÇÃO, 2012, p. 25, grifo nosso)

Diante do exposto sobre as instruções direcionadas ao candidato, outro ponto a ser considerado é a apreensão do tema e, em seguida, a aplicação das habilidades de leitura, interpretação e compreensão para, através da escrita, imprimir a autoria esperada de todo candidato ao ENEM.

Como é possível observar, o Exame trouxe, em 2014, uma discussão acerca da "publicidade infantil em questão no Brasil". Como forma de contextualização, a proposta expôs três textos que discutem a questão. No texto I, por exemplo, são apresentadas as posições assumidas por determinados grupos a respeito da aprovação, em 2014, pelo Conanda, da resolução que considera abusiva a publicidade infantil. Já no texto II, há um dado comparativo, a partir de infográfico, é possível identificar que somente no Brasil não há leis que regulamentam a publicidade, isso quando o país é comparado com outros como: Canadá, Estados Unidos, Reino Unido, Irlanda, França, Itália, Chile, Noruega, Suécia, Dinamarca, Bélgica, Coreia do Sul e Austrália. Em seguida, o Texto III apresenta uma justificativa que explica o motivo pelo qual é preciso preparar a criança, desde pequena, para saber como agir em relação às tendências midiáticas.

A partir da descrição e análise da proposta acima, observa-se que a junção dos textos em uma proposta pode nos inserir em uma determinada formação discursiva, produzindo uma injunção à interpretação já autorizada em nosso contexto, ou seja, o modo como a questão é formulada, como os textos são postos, já nos aponta o que pode e deve ser dito na redação, ou mesmo tenta direcionar para a formação discursiva em que o aluno-candidato precisa se inserir para produzir seu texto, para que, em última instância, seja bem avaliado. Ao levarmos em consideração a sequência textual, os textos selecionados bem como o tema proposto, chegamos à observação de que desde a aprovação de uma resolução que considera abusiva a publicidade infantil, muitas discussões ocorreram favoráveis e contrárias ao fato, no entanto, quando comparamos o Brasil com outros países no mundo, percebemos que aqui é o único lugar cuja regulamentação não existe. Tal fato é relevante, especialmente se levamos em conta que todos os países apontados são do Norte, com exceção do Chile, ou os considerados desenvolvidos, o que nos coloca novamente em um patamar de atraso, situação observada durante os estudos de Silva (1998) sobre o discurso da Cultura, que nos remete ao préconstruído de aceitação passiva de tudo que vem de fora e de falta de desenvolvimento intelectual brasileiro.

Na sequência, o texto aponta que é preciso regulamentar a lei, mas ao mesmo tempo, é necessário preparar a criança para entender as informações recebidas a partir da publicidade e ensinar ao público infantil como analisá-las com criticidade, consciência e responsabilidade. Logo, retomemos o que outrora já colocamos: a leitura e a escrita nos permitem certos gestos interessantes. Um deles é a possibilidade de observar os discursos provenientes de variados textos.

Assim, a partir da análise da produção textual de um candidato deste mesmo ano, verifiquemos como o discurso já posto nos chamados textos motivadores foi percebido e compreendido, qual foi a sua posição sujeito ao construir o próprio texto, marcando uma 
posição significativa em relação ao que foi lido nos excertos e como o candidato se coloca na função autor, tendo em vista o que já discutimos anteriormente. A escolha deste texto foi feita a partir dos seguintes elementos: ano e nota. Trazemos à tona o texto de um candidato da $3^{\text {a }}$ série do Ensino Médio (optamos pelo último ano, por ser este o que fecha o ciclo escolar), buscamos, ainda, um texto que tivesse alcançado uma nota considerada acima da média e próximo à nota máxima (de 1000 pontos). Leiamos a produção de texto, bem como sua análise.

Averiguamos que, já na introdução deste texto, é possível perceber que o candidato faz uma junção de trechos presentes no texto I e no texto III. Constata que a resolução do Conanda é importante, mas a educação para que a "criança" consiga avaliar o que lhe é posto também é, pois isso é uma forma de se preparar para o futuro. Retoma, por sua vez, o discurso do Texto III, quando a partir do termo "blindar", no último parágrafo, explicita que não basta privar a criança de ter contato com os anúncios abusivos, é necessário educá-la. Para ele, pais e escola, especialmente as de rede pública, são responsáveis por capacitar a criança para que seja capaz de reconhecer as estratégias publicitárias de convencimento. Isso ocorrerá a partir de esclarecimento sobre os propósitos publicitários e capacidade para reconhecimento das estratégias argumentativas. Ambas as situações serão possíveis através de atividades extracurriculares como debates e palestras.

O texto, dessa forma, apresenta uma proposta de intervenção detalhada, explícita e articulada com o restante do texto, além de estratégias argumentativas que tentam persuadir o leitor a acreditar que a "criança" não tem o mesmo discernimento que o adulto para separar o real do ilusório. Além disso, também aponta inúmeras consequências negativas resultantes de uma exposição à mídia: consumismo exacerbado, dívidas, apego a bem materiais e a própria mercantilização das relações sociais.

Tudo isso evidencia que o candidato foi capaz de identificar e ratificar o discurso hegemônico já posto na proposta de redação e acrescentar as consequências não explícitas na coletânea, para sustentar sua argumentação. Assim, ele constrói o texto de uma forma a aplicar os conhecimentos linguísticos necessários para apresentar de maneira coesa e coerente, na modalidade escrita da língua (repetição formal), o resultado de sua leitura, compreensão e interpretação não só do excerto, mas do discurso já naturalizado (repetição histórica) que sustenta a proposta e sua produção textual, mesmo que isso implica repetir dadas estruturas.

Outra questão a se observar é a de que o candidato isentar o governo de ter que solucionar qualquer problema relacionado às questões midiáticas, assim como fazem os textos de apoio. Este é um aspecto interessante de observarmos, pois demonstra que o candidato entendeu o que os documentos propõem quanto a quem deve solucionar os problemas: instâncias sociais que estejam mais próximas de quem de fato é atingido pelo problema. Logo temos que para o Guia, conforme já mencionamos, ao mostrar-se capaz de identificar que instância social ou instituições têm mais condições de solucionar os problemas colocados, o candidato demonstra ser capaz de praticar a autoria. 


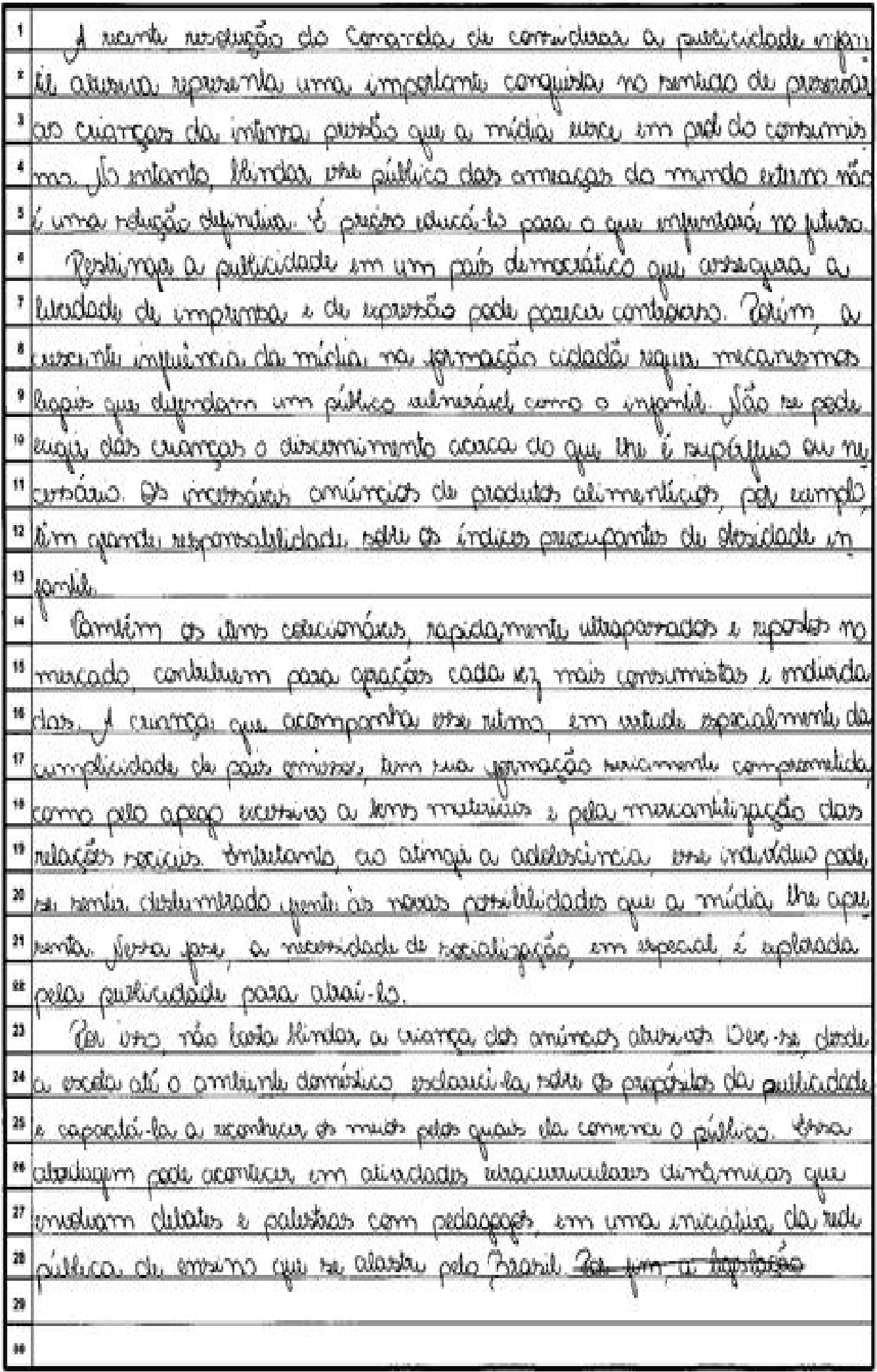

Figura 10 - Produção de texto de um candidato ao ENEM 2014.

Entre a formulação da prova do ENEM e o efeito-leitor, portanto, temos várias posições: a posição dos documentos, a posição do Guia, as posições dos textos que 
compõem a Proposta de Redação, enfim, em todo discurso há um sujeito. Podemos tomar, por hora que, a estrutura da Proposta, bem como os textos que a compõem representam o sujeito na posição de quem propõe o tema, logo o institucional e o candidato representa o sujeito na posição de que precisa passar em uma prova elaborada pela mesma instituição que solicita a ele uma proposta de intervenção para um problema social, afinal, "não há discurso sem sujeito nem sujeito sem ideologia, sujeitos todos somos desde que falamos" (ORLANDI, 1998, p.13). Somos sujeitos desde que falamos, no entanto, "o sujeito só se faz autor se o que ele produz for interpretável." (ORLANDI, 2004, p. 70). Além disso, ser autor

É o princípio do agrupamento do discurso, unidade e origem de suas significações, o que o coloca como responsável pelo texto que produz. A noção de sujeito não recobre uma forma de subjetividade, mas um lugar, uma posição discursiva relativa a uma incidência da memória (instância da constituição dos sentidos). A noção de autor é já uma função da noção de sujeito, responsável pela organização do sentido e pela unidade do texto (instância da formulação). O autor - a função autor - é tocada de modo particular pela história: o autor consegue formular no interior do formulável e se constituir, com seu enunciado, numa história de formulações. (ORLANDI, 1998, p. 13)

Além do processo de autoria implicar a organização de sentido, a constituição do autor, supõe, também, a repetição, uma vez que, parafraseando Orlandi (1998), é impossível ao autor evitar a repetição, já que ela é necessária para que seu enunciado faça sentido e seja interpretável. No entanto, tal repetição é feita de modo particular, fato que instaura um lugar de interpretação no meio dos outros. Dessa forma, "a repetição é assim, para o autor, parte da história e não mero exercício mnemônico. Inscrevendo sua formulação no interdiscurso, na memória do dizer, o autor assume sua posição de autoria, produzindo um evento interpretativo, ou seja, o que faz sentido" (ORLANDI, 1998, p. 13).

No caso específico que analisamos, percebemos que os candidatos se inserem no grupo da repetição histórica (Orlandi, 1998), uma vez que esta se dá quando um dizer é colocado em meio a outros, inscrevendo o que se diz em uma memória discursiva posta, inclusive, desde a colonização do Brasil, segundo a qual somos um povo que copia outros. Essa repetição histórica, portanto, se diferencia tanto da repetição empírica, que seria o mero exercício mnemônico, aquele que não historiciza, quanto da repetição formal, que é a mera técnica de produzir frases de modo organizado e que também, segundo Orlandi, 1998), não historiciza.

Verificamos que a inscrição do dizer do candidato no repetível histórico traz para esse então sujeito autor a questão da interpretação: "nesse caso o dizível é o repetível, ou seja, o que é passível de interpretação num movimento de inscrição e deslocamento simultâneos" (ORLANDI, 1998, p. 14). 


\section{Conclusão}

Para concluirmos nossa reflexão, retomamos o que inicialmente propusemos acerca da verificação da efetivação da assunção da autoria, no caso em questão que analisamos neste artigo, tal efetivação ocorreu, especialmente em um sujeito inserido em uma formação discursiva específica, o que o levou a reproduzir e reforçar a legitimação de um discurso dominante desde a colonização do Brasil, depois de ter sido constituído pela língua e de tê-la como condição para aplicação da leitura e da escrita. Nossa tentativa foi, pois, identificar, a partir das reflexões e de análise, pistas que o texto produzido pelo candidato ofereceu, a fim de compreendê-lo e identificarmos de que modo a inscrição do dizer do candidato se apresenta como historicamente repetível e mesmo assim traz para esse sujeito sua capacidade de se mostrar como autor, afinal: "nesse caso o dizível é o repetível, ou seja, o que é passível de interpretação num movimento de inscrição e deslocamento simultâneos" (ORLANDI, 1998, p. 14).

\section{Referências}

AUROUX, Sylvain. A revolução tecnológica da gramatização. Trad. Bras. $2^{\mathrm{a}}$. ed. Campinas:. Editora da Unicamp, 2009.

FIORIN, J.L.; PLATÃO, S. Lições de textos: leitura redação. São Paulo, Ática, 2002.

KOCH, I.G.V. Ler e escrever: estratégias de produção textual. $2^{a}$. ed., $1^{a}$ reimp. São Paulo: Contexto, 2012.

MINISTÉRIO DA EDUCAÇÃO - INEP - A Redação no Enem 2012 [Guia do Participante]. Brasília, 2012.

ORLANDI, E.P. Formação ou Capacitação? Duas formas de ligar sociedade e conhecimento. Em: FERREIRA, E.L.; ORLANDI, E.P. (Orgs.). Discursos sobre a inclusão. Niterói, RJ: Intertexto, 2014.

O estatuto do texto na História da Reflexão sobre a linguagem. Em: Discurso e Texto. Campinas: Pontes, 2008.

- Uma história do conhecimento, uma história da língua. Em: Língua e conhecimento linguístico. São Paulo: Cortez, 2002.

História das Ideias Linguísticas. Construção do saber Metalinguístico e Constituição da Língua Nacional. Campinas: Pontes, 2001.

Paráfrase e polissemia. Rua, NUDECRI, Campinas, 9-16, março 1998.

PÊCHEUX, M. Papel da Memória. Em: ACHARD, Pierre et al. . Papel da memória. Campinas: Pontes, 1999. p. 49-57. 
PFEIFFER, C.R.C. O leitor no contexto escolar. Em: OELANDI, E. (Org.). A leitura e os leitores. Campinas: Pontes, 1998.

Que autor é este? Campinas. Dissertação. Mestrado em Linguística, Instituto de Estudos da Linguagem, Universidade Estadual de Campinas, Campinas, SP, 1995.

SILVA, M.V. da. História da Alfabetização no Brasil: A Constituição de Sentidos e do Sujeito da Escolarização. Tese. Doutorado em Linguística, Instituto de Estudos da Linguagem, Universidade Estadual de Campinas, Campinas, SP, 1998.

PORTAL EDUCAÇÃO. Direito. Disponível em https://www.portaleducacao.com.br/direito/artigos/50880/o-que-a-constituicao-dizsobre-a-cidadania. Acesso em 20 de out. 2016.

TFOUNI, L.V. A abordagem histórica do letramento: ecos da memória na atualidade. SCRIPTA, n. 32, v. 17, Belo Horizonte, 23-48, 2013.

Artigo recebido em: abril de 2017.

Aprovado e revisado em: setembro de 2017.

Publicado em: novembro de 2017.

\section{Para citar este texto:}

LIMA, Magna Leite Carvalho. Texto e autoria em gestos de leitura e escrita no ENEM. Entremeios [Revista de Estudos do Discurso, on-line, www.entremeios.inf.br], Seção Estudos, Programa de Pós-Graduação em Ciências da Linguagem (PPGCL), Universidade do Vale do Sapucaí (UNIVÁS), Pouso Alegre (MG), vol. 15, p. 127-150, jul. - dez. 2017.

DOI: http://dx.doi.org/10.20337/ISSN2179-3514revistaENTREMEIOSvol15pagina127a150 